\title{
Problem-Based Learning: Student Perceptions of its Value in Developing Professional Skills for Engineering Practice
}

\author{
Una Beagon \\ Technological University Dublin, una.beagon@tudublin.ie \\ Dervilla Niall \\ Technological University Dublin \\ Eabhnat Ni Fhloinn \\ Dublin City University, eabhnat.nifhloinn@dcu.ie
}

Follow this and additional works at: https://arrow.tudublin.ie/engschcivart

Part of the Engineering Commons

\section{Recommended Citation}

Ni Fhloinn, E., Beagon, U. \& Niall. D. (2018) Problem-Based Learning: Student Perceptions of its Value in Developing Professional Skills for Engineering Practice, European Journal Of Engineering Education, 16 October 2018. DOI: 10.1080/03043797.2018.1536114

This Article is brought to you for free and open access by the School of Civil and Structural Engineering at ARROW@TU Dublin. It has been accepted for inclusion in Articles by an authorized administrator of ARROW@TU Dublin. For more information, please contact arrow.admin@tudublin.ie, aisling.coyne@tudublin.ie, gerard.connolly@tudublin.ie.

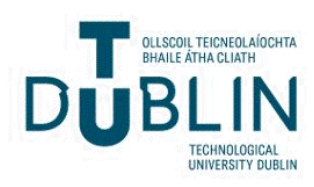


"This is an original manuscript / preprint of an article published by Taylor \& Francis in [European Journal Of Engineering Education] on [16 October 2018], available

online: http://www.tandfonline.com/[ https://doi.org/10.1080/03043797.2018.1536114

\title{
Problem-Based Learning: Student perceptions of its value in developing professional skills for engineering practice
}

\author{
Úna Beagon ${ }^{\mathrm{a}}$, Dervilla Niall ${ }^{\mathrm{b}}$ and Eabhnat Ní Fhloinn ${ }^{\mathrm{c}}$ \\ ${ }^{a, b}$ College of Engineering and Built Environment, Dublin Institute of Technology, \\ Dublin, Ireland
}

${ }^{c}$ School of Mathematical Sciences, Dublin City University, Dublin, Ireland

${ }^{a}$ https://orcid.org/0000-0001-6789-7009

${ }^{c}$ https://orcid.org/0000-0002-3840-2115

Corresponding Author: eabhnat.nifhloinn@dcu.ie 


\title{
Problem-Based Learning: Student perceptions of its value in developing professional skills for engineering practice
}

\author{
This study explores students' perceptions of the effectiveness of a Problem-Based \\ Learning (PBL) design project, taken as part of a first-year engineering module, \\ in developing professional skills needed for engineering practice. Students \\ completed surveys before and after the PBL group project, and produced personal \\ reflections on the process. The closed survey questions were analysed \\ quantitatively and the main themes from the reflections outlined using General \\ Inductive Analysis. Students rated themselves as having improved across a range \\ of professional skills as a result of the project, with particular emphasis on \\ teamwork, communication skills, understanding of the design process and self- \\ directed learning. In addition, they highlighted improved confidence, as well as \\ new friendships they developed, an important element of a module like this as \\ they transition from secondary to higher education. They were particularly \\ positive about the scaffolded approach taken within the PBL project in terms of \\ its contribution to their learning.
}

Keywords: engineering practice; professional skills; Problem Based learning; employability; transition

\section{Introduction}

This paper reports on students' perceptions of a Problem-Based Learning (PBL) project within a first-year engineering Design Project module, to assess how effective it can be in embedding engineering practice into a module at the crucial transitional point as students move from secondary to tertiary education. The project draws on the idea that practicing engineers in industry need much more than a technical understanding of engineering science and mathematics, or the ability to use new software. This aspect of practice has been coined 'socio-technical' and reflects the reality that engineering practice intertwines social (people) and technical (engineering) factors (Trevelyan 2014). There have been calls for engineering practice to be more deeply embedded in the engineering curriculum (Trevelyan 2014; Sheppard et al. 2009) and several aspects 
of this project were designed to simulate engineering practice experiences. Our study specifically sought to assess the students' perceptions of the effects of a PBL project on enhancing skills needed for engineering practice. Investigation of students' perceptions gives us an in-depth view of their conceptions, expectations and experiences and enables us, as educators, to use those findings to enhance such approaches in the future. PBL projects have been shown to provide context, interest and motivation to students in addition to allowing opportunities to develop skills in teamwork, communication, negotiation, innovation, research, leadership, environmental responsibility and business acumen (RAE 2007; Beanland and Hadgraft 2013), making them potentially well-suited to the introduction of engineering practice into an early stage of students' engineering education.

With the first two authors having spent 20 years each as engineers in industry prior to joining academia, the team involved in designing this study knew the importance of bringing real-world experiences into the classroom, and mirroring what happens in industry in a supportive environment for their students. The study sought to answer the research question: 'Do students perceive $P B L$ projects to be a valuable teaching pedagogy to embed engineering practice into early engineering education, by enhancing their professional skills?'

Students were asked to complete a survey before and after the project to identify how successfully the PBL approach contributed to the development of specific graduate skills upon completion of the project. Students were also asked to submit a personal reflection on the project and a Grounded Inductive Analysis was carried out to identify emerging themes from the reflections.

The findings provide us with an insight into how students perceive the value of a PBL project in developing non-technical skills within their engineering programmes. 
Furthermore, the analysis highlights the challenges faced by first-year students in an engineering programme in general; many of which do not relate to academic or technical issues. Students highlighted issues relating to working in teams and dealing with conflict, the importance of good communication and also the sense of accomplishment achieved from completing an engineering project. Findings also highlight the central role that scaffolding (team guidance, written briefs / templates / models) played in their project success.

As a first-year module, the project highlighted to students, shortly after their transition from secondary school to tertiary education, the wide scope of engineering practice and the importance of developing skills beyond technical or academic ability in engineering. Understanding student experiences and the role of support mechanisms can help educators design inclusive projects to support students more effectively during the vulnerable early days of their journey to finding their identity as engineers.

\section{Literature Review}

In order to provide some context for this study, we will now review the most pertinent literature on Engineering Practice and Problem Based Learning.

\subsection{Engineering Practice}

Engineering as a form of design or construction can be dated back as far as 3000BC, when clay tablets from the Mesopotamian period show evidence of mathematical calculations including algebraic equations, volumes of masonry and areas of land (Kirby et al. 1990). Since then, the engineering profession has not only expanded in scope, or fragmented into specialist disciplines, but the way in which engineers train and practice has also changed dramatically. In the 19th Century, Civil Engineers in 
Britain were trained under an apprenticeship system and learned at the knee of another engineer, emulating their patron. Students learned the basics of load transfer but focused on practical application and empirical knowledge to produce engineering solutions to infrastructural problems (Clarke 2012; De Figueiredo 2014).

The civil and structural engineering profession in particular has changed dramatically since then. New materials have been invented; new ways of analysing structures and modelling situations have been designed. Computers now have the processing power to analyse more complex structures, and to a finer degree, thus producing more efficient designs. This change is also reflected in engineering education. The profession has morphed from an apprenticeship system, through to a focus on theory through engineering sciences and mathematics, and more recently back to a recognition that engineering degree programmes must include more real life applications of practice (Clarke 2012; Trevelyan 2014; Sheppard et al. 2009). It is not only the technical and theoretical issues that have changed the way engineers work. Today’s world is in constant turmoil with continually accelerating technological transformation and changing demographics. Engineers in the $21^{\text {st }}$ century need to have the skills and competencies to work in multi-disciplinary teams, transcend international boundaries and deal with globally complex issues in unfamiliar surroundings. There is no doubt that engineers today need technical expertise, but a wide range of other skills are also required to enable engineers to collaborate successfully in the culmination of a project (UNESCO 2013; ASEE 2013; Wulf 2008; Miller 2015).

De Figueiredo (2014) proposed that engineers have multiple identities, based on four dimensions: the engineer as a scientist, as a craftsman, as a designer and as a social, business and management expert. Each engineer, depending on their experience, personal style and current circumstances will have varying aspects of each dimension 
within their engineering practice. This leads naturally to the question 'What is Engineering Practice?’

Williams and Figueiredo (2014) undertook a survey and in-depth interviews with Portuguese engineers. One research question investigated how much time engineers spent on different activities in the workplace. An initial survey of junior engineers (those with less than 7 years' experience) showed that $56 \%$ of their time was engaged in activities involving other people (meetings etc) whilst $44 \%$ of their time was spent on individual activities such as designing, drawing, surveying, testing etc. What is surprising however is that the result does not differ dramatically from more senior engineers in management positions within organisations (Trevelyan 2010) and suggests that engineering practice, even for new graduate engineers, demands the skill-set required to work effectively in teams. Williams and Figueiredo, $(2014,167)$ term this the "socio-technical aspects of engineering”.

A balance must be sought between the proportion of teaching which focusses on engineering science fundamentals versus the benefits of learning by doing or emulating engineering practice. In fact, historical texts have shown us that the engineering education community have indeed flipped from one ethos to another and back again. It appears the balance has not yet been achieved. Most recently there is increased recognition that academic institutions should focus on preparing engineers for the workforce and several authoritative figures call for curricula redesign. Miller (2015) talks about “rebalancing engineering education” whilst Clarke (2012, 211) recognises that we must now "embrace transformational change”. Seely $(2005,125)$ refers to "reinventing the wheel" in relation to curriculum reform and reminds us that engineering educators have walked this path before. 


\subsubsection{Required skillset for engineering practice}

There are many references in the literature to the lack of competencies in engineering graduates from an employer’s viewpoint (Grinter 1955; Spinks et al. 2006; RAE 2007; IET 2016; ASEE 2015). The seminal Henley Report commissioned by the Royal Academy of Engineering (RAE) in 2007 specifically looked at the current and future needs of engineering graduates. The research methodology included in-depth interviews with practitioners, and graduate focus groups along with a large scale survey of over 400 employers. The results indicated that there were deficiencies in the skills of engineering graduates available in the UK and that this had an effect on industry growth (Spinks et al. 2006). Of particular concern was a lack of ability of graduates to solve real world problems and the report encourages HEIs to enhance curricula with opportunities for students to gain practical work experience. "Practical application, theoretical understanding, and creativity and innovation” are identified as the skills needed for the future graduate. The report suggests three roles for the future engineer; technical expert, integrator and change agent. The skills needed to achieve this are proposed as "graduates who combine technical expertise with practical ability, backed up by strong interpersonal skills, including an awareness of commercial realities” (Spinks et al. 2006, 59). A factor analysis was carried out on the responses within the interviews, which revealed two underlying dimensions (factors). The results indicated that graduates need competency in Defining Skills (Technical domain) and Enabling Skills (Social Domain). The defining skills are technical and are those skills which “define” what an engineer does. The enabling skills however, enable the engineer to work effectively in a social domain and are not necessarily unique to engineers. These results compare closely with the socio-technical terminology used by Trevelyan (2014) and Williams and Figueiredo (2014). 
Kövesi and Csizmadia (2016) undertook 15 semi-structured interviews with a range of engineering practitioners in Hungary. They identified several aspects where young engineers' skills mismatched the expectations of industry. These included lack of initiative, inability to work independently and lack of engineer-style cognition. Upon further analysis, the authors proposed that this term can be explained as a combination of analytical thinking, structured problem solving and having a systematic and holistic perspective.

Communication skills in particular seem to be of immediate concern, as Sageev (2001) found in a survey conducted in 1999. He argued that engineers today work in a fast-paced and competitive workplace and they need to be able to communicate technical information to a wide range of audiences. Similar issues were identified in Ireland when, in 2011, the Institutes of Technology commissioned a study to look at the strengths and weaknesses of engineering programmes using feedback from employers (IOT 2011). The report recommends that “(t)he teaching of key non-technical skills such as oral and written communication should be enhanced and further integrated into the earlier years of the engineering programmes" (IOT 2011, 8).

A recent review of UK engineering companies undertaken by the Institution of Engineering and Technology again highlighted a skills gap with graduates considered to be “not work-ready” (IET 2016). The skills deficit of particular mention included work ethic, practical experience, business acumen, and leadership and management skills.

In 2013, the American Society for Engineering Education (ASEE) began a consultation process to develop a new strategy for engineering education to meet industry's needs, the purpose of which was to identify competencies, skills and qualities required of future graduates. The outcome was a T-shaped engineering graduate, with a broad knowledge base and ability to work within a diverse team, in addition to deep 
technical expertise in a particular area. The T-shaped graduate idea is not new; as Miller (2015) attests, it developed from the idea of hybrid managers in relation to IT services in 1990 (Palmer 1990), and was first drawn by Leonard-Barton (1995). Whilst the attendees agreed that engineering fundamentals were still a priority, communication skills, motivation, business acumen and curious learning capacity, ethical standards, critical thinking, risk assessment and persistence were all identified as necessary.

\subsection{Problem-Based Learning (PBL)}

It is clear therefore that skills associated with the social aspect of engineering practice have become an important aspect of our students' education. The next step is to investigate which teaching strategies develop these skills.

Problem-Based Learning (PBL) has been used for decades in engineering education, largely drawn from work in the field of medicine since the 1960s (Mills and Treagust 2003). Many educators see group-work as an essential aspect of PBL (Barrows 1988). In PBL, students are presented with a problem first, and that problem forms the core of the learning process (De Graaf and Kolmos 2003). This educational approach is process-oriented (rather than product-oriented). It provides students with experience of complex, ill-defined projects as well as collaborative learning formats that require teamwork, collective decision-making, and self-directed learning. For effective PBL, educators should provide scaffolding, such as instruction on how to work effectively in a team (Prichard et al. 2006) and examples that groups can use to direct their own learning (Barrows 1988).

Several studies have been carried out to determine if there is a link between independent learning and development of soft skills, or student-centred learning approaches and development of generic skills (Iborra et al. 2014; Fernandes 2014; Le and Tam 2008). It has also been stated that PBL can be an effective vehicle for 
improving soft skills in graduates (Veldman et al. 2008) but evidence is lacking in this study to support this statement. Significant work in recent years showed improvements in transferable skills in chemical engineering graduates with a project-centred curriculum and the use of integrated projects (Le and Tam 2008; Grant and Dickson 2006; Crosthwaite et al. 2006; Abdullah et al. 2012).

Several studies have been carried out using PBL in a civil engineering context and results have indicated success in increasing the technical knowledge of the particular subject in the students’ psyche (Baharom et al. 2012). Ahern (2010) presented two case studies of PBL implementation in transportation courses for civil engineering students. The results showed increased engagement from students and evidence of critical thinking and deep learning. PBL does have its pitfalls however. Both Ahern (2010) and Iborra et al. (2014) report on the importance of using well trained staff and having sufficient resources to implement PBL. Furthermore, both also note that some students do not appreciate the PBL approach and feel the time could be better used in a traditional lecture-based approach. This concurs with Fernandes (2014) who also highlighted issues raised with regard to the time a student spent on a PBL project compared to the apportionment of marks.

This literature review has revealed the importance of preparing engineering students for engineering practice and in particular the socio-technical aspects of working in a team. The use of PBL is lauded as a way to enhance engineering education and this project aimed to ascertain the students' perceptions of the value of a PBL project in enhancing skills required for practice. 


\section{Methodology}

This study was approached with an interpretivist ontological position and a constructivist epistemological perspective (Savin-Baden and Major 2013; Guba and Lincoln 1994; Cohen, Manion and Morrison 2011; Marton and Saljo 1976). Constructivism came from several cognitive approaches that thought of knowledge as being constructed rather than discovered. It is based on the ontological assumption that there are multiple realities, formed in the human mind as a result of experiential and social constructions (Marton and Saljo 1976). Although some of these realities may be common across a group of people, they are personal to each individual. Findings from a constructivist investigation are created by the interaction between the object and the researcher and constructions are refined and elicited through interpretation of the data. As such, we propose that each student has their own unique experience of a situation and this is constructed through their individual interaction with the situation, which in this case study is a group PBL project. This perspective shaped the development of our methodology for this study. Here, we discuss the design of the project itself, the sample population studied, and the approaches used to analyse the collected data.

\subsection{Project design}

This project was inspired by work carried out in the University of Limerick (Philips 2007), where a similar bridge-design and building project resulted in reported success in student engagement and enthusiasm, as well as active learning.

In keeping with pedagogical theories underpinning PBL, the students were given little guidance and few specifications to complete the bridge design, with instruction focused on the team design process rather than product (Barrows 1988). The problem was defined as 'Design a pedestrian bridge to span 6m across a river for use in 
emergency situations in Nairobi'. The only limiting criterion was that the bridge design and construction methods needed to take cognisance of the local conditions, materials and skilled labour available in Nairobi.

However, as it was considered that a first-year student group still getting to grips with tertiary education may not quite grasp the concept of self-directed learning, a detailed supporting document was provided to assist with the management of the project. This document provided students with information such as a timeline; roles within the team and their associated responsibilities; a weekly task checklist; a template of meeting minutes; relevant references on basic structural analysis design; and a "team charter” with suggested expectations, rules of conduct and penalties for underperformance (for peer assessment purposes), to be defined by each team at the start of the process.

The project was developed with the aim of enhancing professional skills such as; teamwork, independent research, the communication of results, (both orally and graphically), the application of engineering concepts and design tools to solve realworld problems. Furthermore, the project aimed to simulate engineering practice and to give students an opportunity to perform the socio-technical aspects of engineering practice highlighted by Trevelyan (2014). These include building relationships and trust, self-organisation, developing others, co-ordinating others and self-assessment.

It ran over a 6-week cycle with approximately forty students per cycle and groups consisted of four to five members. The groups had four weeks to work on their design, after which they gave an oral presentation of their solution to their class.

The tutors then selected a winning group, who had the opportunity to build and test the full scale bridge over a pond on campus. The remaining groups constructed balsawood models, which were also tested in the lab. The construction activity took 
place in week 5 with testing in week 6 . The 4-hour weekly tutorial class was purposefully ill-defined, with the only requirement being that each team started with a 'Design Team Meeting', mirroring what happens in industry, and closed each session with a presentation of their progress. In line with a PBL approach, tutors circulated providing guidance and advice and most importantly feedback, but no formal teaching was carried out.

The marking scheme was composed as shown in Table 1 [Table 1 near here]:

Table 1: Marking scheme for the PBL project, broken down into its various components.

\begin{tabular}{|l|c|}
\hline \multicolumn{1}{|c|}{ Area } & Contribution to Mark \\
\hline Teamwork & $40 \%$ \\
\hline Quality of bridge design & $20 \%$ \\
\hline Individual reflection & $5 \%$ \\
\hline Group presentation in week 4 & $5 \%$ \\
\hline Project folder: & \\
\hline Minutes of meetings & $5 \%$ \\
\hline Research & $5 \%$ \\
\hline Analysis & $5 \%$ \\
\hline Method of construction & $5 \%$ \\
\hline Drawings & $5 \%$ \\
\hline General presentation & $5 \%$ \\
\hline
\end{tabular}

The tutors allocated $60 \%$ of marks, based on the quality of the bridge design, individual reflection, project folder, and group presentation. The teamwork mark (40\%) was determined for each individual within their group, based on their "team charter". Each group was required to record the running teamwork score (out of $40 \%$ ) for each person 
in the minutes of their design team meeting every week. This enabled them to develop healthy work practices where issues that arose were addressed immediately rather than creating a conflict situation at the end of the project. The confidential 500-word reflections were due one week after completion of the project. Students were asked to address the following topics within their reflections: (1) research and design; (2) working in a team; (3) managing a project; and (4) self-confidence.

\subsection{Data collection}

A total of 98 students were involved in this study, over three cycles. Students were surveyed anonymously before and after the project, and were asked to self-assess their ability in specific skills. They were also asked to score on a scale of $0-10$ their increase in ability under these same headings having undertaken the project.

In addition, the students' individual reflections were analysed to provide further insight into student perceptions of the PBL experience. It must be acknowledged that assigning credit for completion of the reflections inherently lowers the degree of authenticity and validity. However, it does tend to provide a more holistic account than including only volunteers. To encourage students to provide full and accurate selfreports, students were assured that marks were awarded based on how deeply they reflected on their experience, not on whether their reflections were positive or negative. Marks were provided to encourage submission but formed just 5\% of the overall grade within a project worth 2.5 ECTS (European Credit Transfer System) credits, where 60 ECTS are required per academic year. This system was designed to encourage participation and honest reflection. Only students who had completed participant consent forms, in accordance with the Institution's Research Ethics Procedures were included in the data pool. 


\subsection{Data analysis}

The data collected was analysed in two ways: using a quantitative approach on the surveys to determine the influence of the project on improving specific graduate skills; and qualitatively to identify the themes emerging from the student reflections. The survey questions allowed students to answer on a five-point or ten-point scale, so these results were collated and represented graphically. The students’ written reflections were then analysed using a General Inductive Approach (GIA) (Thomas 2006) to produce descriptions of the most important themes uncovered. The method is similar to Grounded Theory, with the exception that Grounded Theory seeks to distil a hypothesis or theory from the data (Glaser et al. 1968). Rather than proposing a theory, using GIA, we aimed to provide the reader with understanding of what these PBL students experienced.

Seventy-one reflections were analysed for this study. Names were removed and each submission was assigned a random code, with codes for male students beginning with "M" and those for female students beginning with "F". Reflections were then uploaded into NVivo and coded using the recommendations for GIA. Coding was undertaken by two of the authors separately. The researchers initially read all of the text data and independently coded specific text segments of interest, which were allocated labels according to the emerging theme using an inductive approach. At this point, the individual authors compared outcomes and refined categories through dialectical agreement, searching for synthesis and reducing overlap. The data set was reviewed in light of the agreed categories and further refined, to derive a set of descriptive themes, as is standard in "independent parallel coding” (Thomas 2006). 


\section{Survey results}

We will firstly consider the quantitative results derived from the survey questions.

There were three main questions which we considered in this study and these are detailed below.

\subsection{Prior experience}

Given that the cohort involved was comprised of first-year students, with the potential of a wide variety of prior experiences based on their secondary education and general life-skills, students were asked to indicate their familiarity with skills such as research, self-directed learning, technical drawing and so on. The results are presented in Figure 1 [Figure 1 near here].

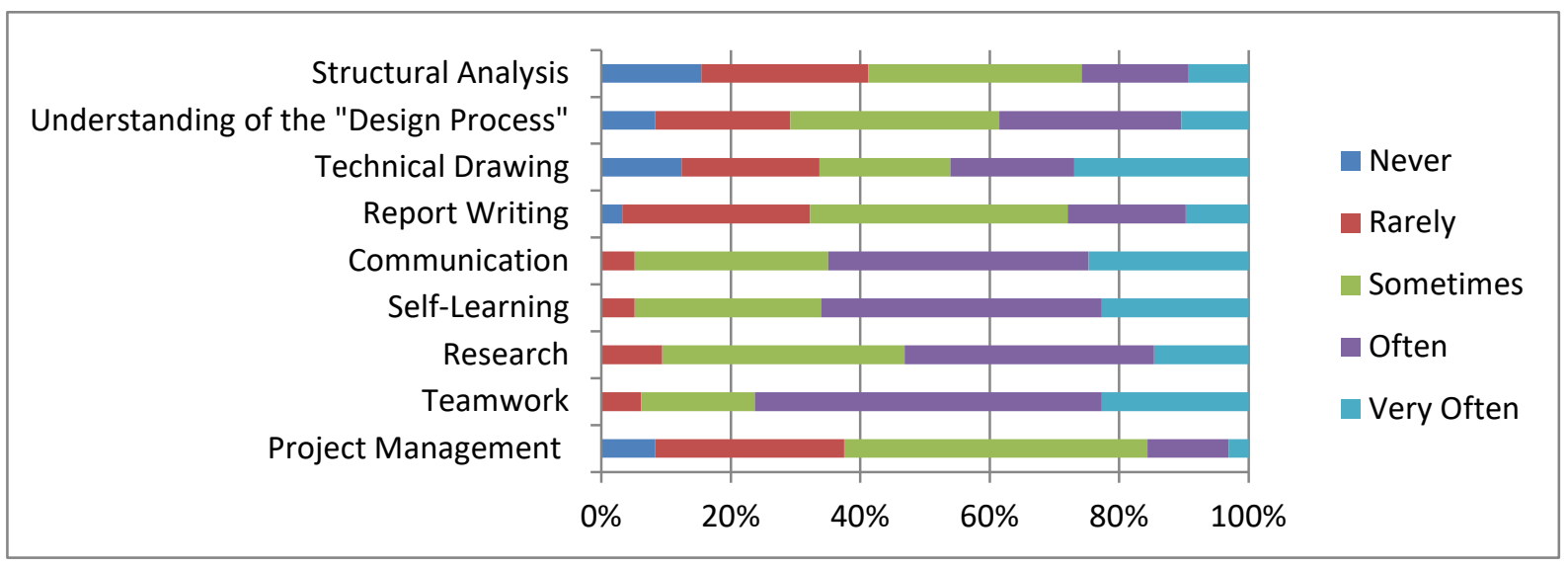

Figure 1: Results of student responses to the question: "Have you had any prior experience which allowed you to develop your ability in the skills listed below?”

It can be seen from Figure 1 that areas such as structural analysis, project management, technical drawing, report writing, and understanding the design process are all unfamiliar territory for $30-40 \%$ of the student respondents. However, even within these areas, there is a diverse range of experience, with $41 \%$ of students saying they often or very often experienced technical drawing in the past, while only $15 \%$ saying similar about project management. 


\subsection{Skills development.}

One of the main aims of the project was to consider whether the use of PBL in a Design

Project module had an impact on professional skills and preparing students for engineering practice. To investigate student perceptions of this impact, students were also asked to score themselves before and after the project on their own ability within the specific skills mentioned above. The 100\% stacked bar chart in Figure 2 shows the scores for before and after the project on each skill [Figure 2 near here].

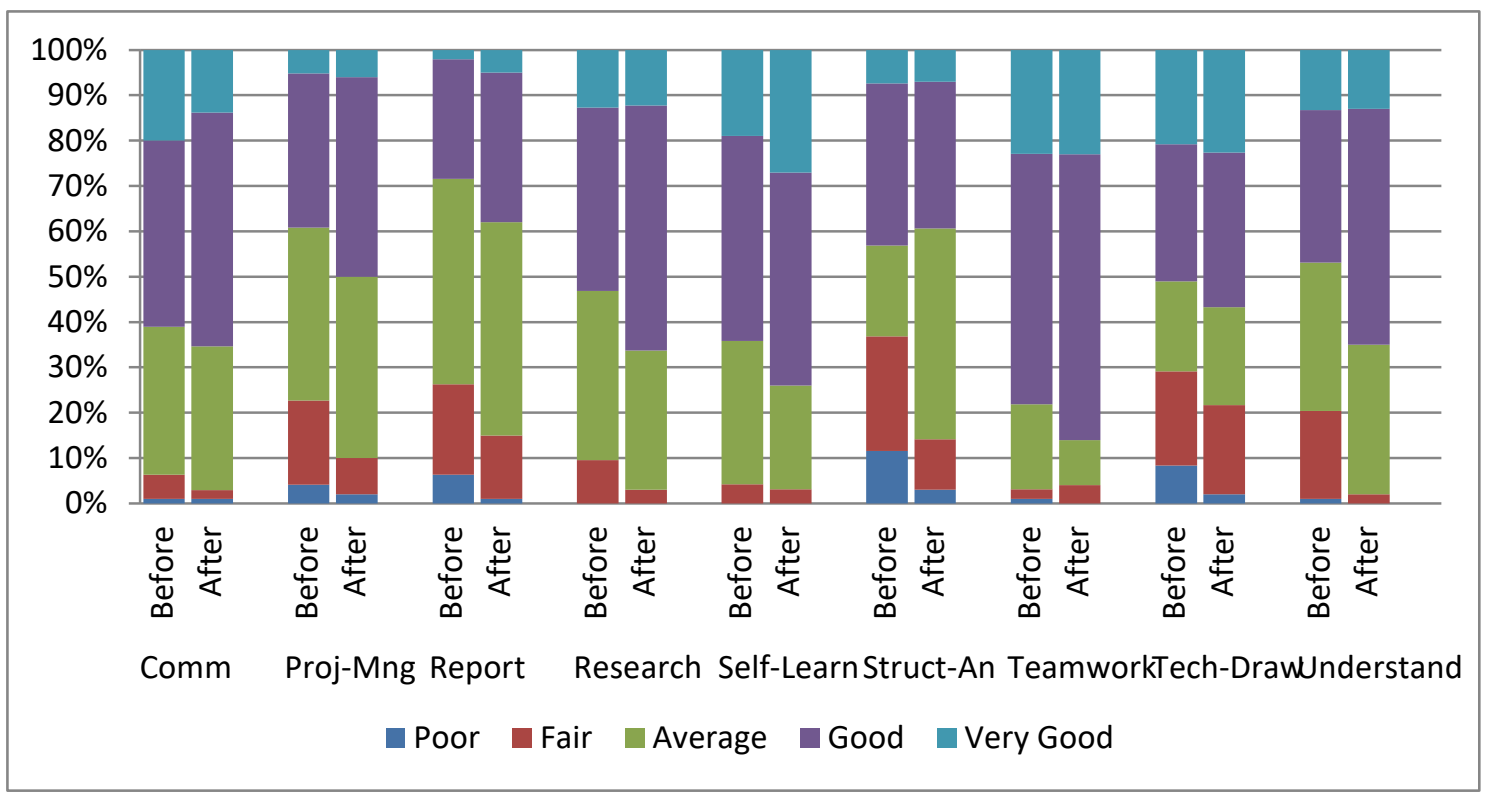

Figure 2: Student responses to the question: "Please indicate how you would rate yourself in the skills listed below” both before and after they took part in the PBL project. "Comm” is communication; "Proj-Mng” is project management; "Self-Learn" is self-directed learning; "Struct-An” is structural analysis; "Tech-Draw” is technical drawing; "Understand” is understanding the design process.

As can be seen in the chart, a higher percentage of students rated themselves as "good" or "very good" in each of these skills after having undertaken the project. However, given that these surveys were anonymous (to comply with ethical considerations and allow the students to rank themselves honestly), it was not possible to match answers 
from the "before" survey to the "after" survey. With this in mind during the design of the project, a further question was added, asking students to rate their improvement in each area as a result of the project (with 0 being no improvement and 10 being no further improvement possible). The diagram in Figure 3 presents the survey results for mean percentage increase in perceived ability [Figure 3 near here].

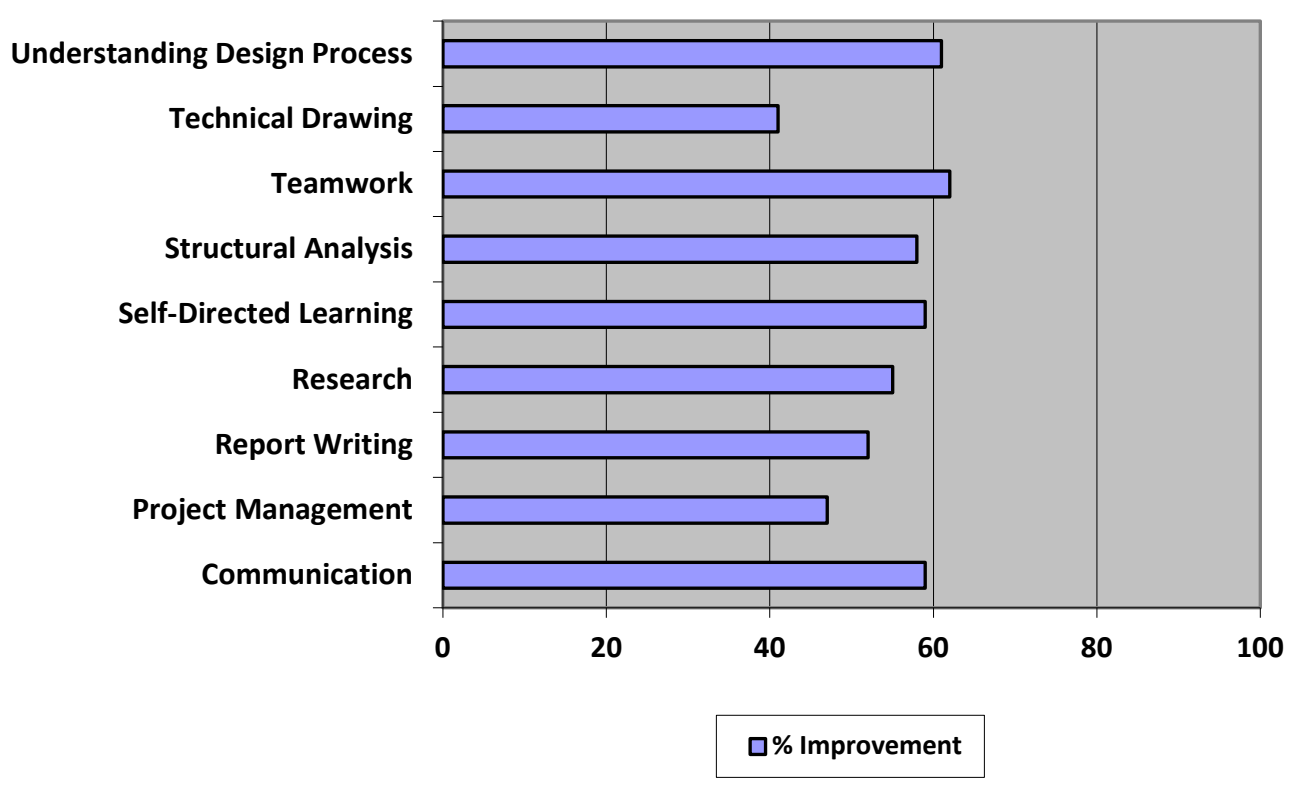

Figure 3: Mean student responses to the survey question: "On a scale of 0 to 10 , how much improvement do you feel you have made in your ability in each of the following skills?”

The diagram indicates that overall, the students perceived that the project had a positive effect on all skills identified. Although the percentage increase was calculated from the mean score, the data was backed up by commentary provided within the reflections by students, as will be further explored in our discussion later.

\section{Reflection categories and themes}

Three broad categories emerged from the GIA of the reflections: (C1) working in a team and learning from others; (C2) individual development (skills and abilities gained and self-realisations); and (C3) reflections on the project itself. The most prominent 
themes can then be grouped under one of these categories as shown in Figure 4 [Figure 4 near here].

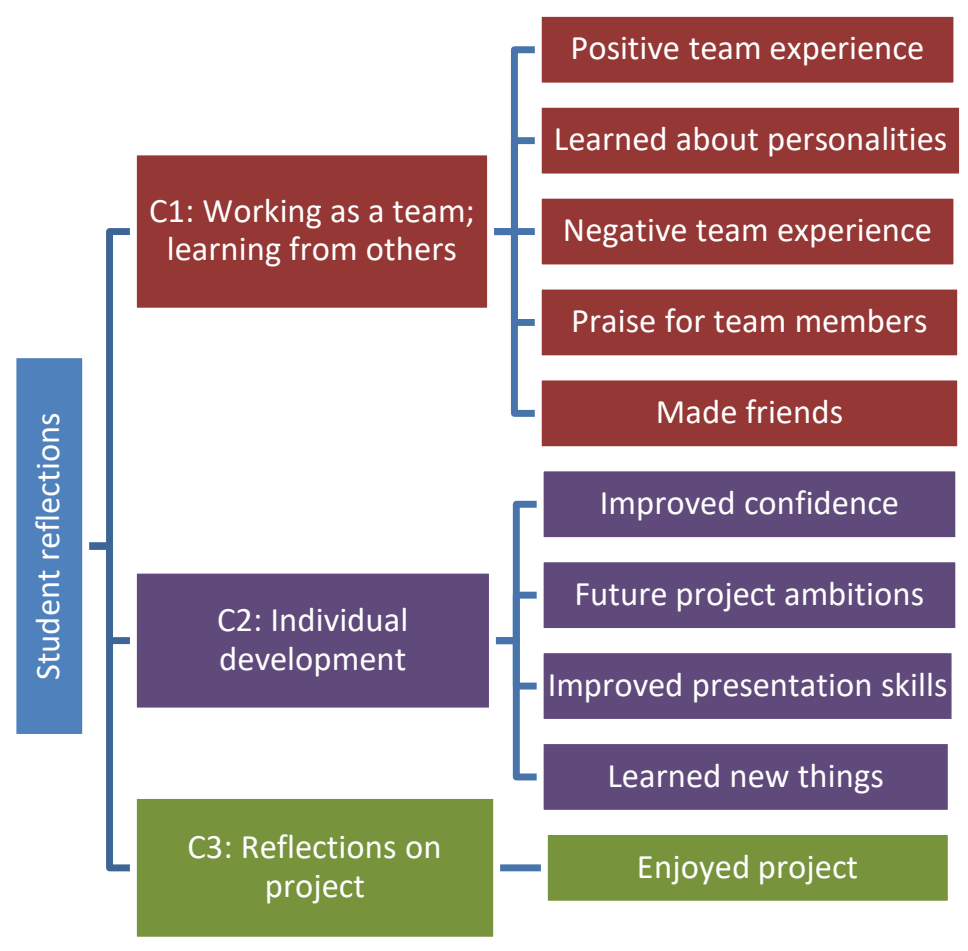

Figure 4: Analysis of student reflections ( $\mathrm{N}=71)$, broken into 3 categories $(\mathrm{C} 1, \mathrm{C} 2$ and C3), with the 10 most common themes shown nested under a category

Some of the prominent themes, such as that of confidence, most likely appeared as a direct result of the prompts students received in the assignment brief. However, other themes emerged without prompting. In Table 2, we identify the ten main themes, each of which appeared in a minimum of $30 \%$ of the reflections. [Table 2 near here] All other themes occurred in fewer than $20 \%$ of reflections and as such are not considered any further here. Note that, although only one theme appears under C3 at this point, other themes were identified in this category but only appeared in a small number of reflections.

\begin{tabular}{|l|c|c|c|}
\hline Theme & Category & \# Respondents & \% Respondents \\
\hline Improved confidence & C2 & 55 & $77 \%$ \\
\hline Positive team experience & C1 & 52 & $73 \%$ \\
\hline
\end{tabular}




\begin{tabular}{|l|c|c|c|}
\hline Enjoyed project & C3 & 31 & $44 \%$ \\
\hline Learned about personalities & C1 & 29 & $41 \%$ \\
\hline Future project ambitions & C2 & 27 & $38 \%$ \\
\hline Improved presentation skills & C2 & 26 & $37 \%$ \\
\hline Negative team experience & C1 & 26 & $37 \%$ \\
\hline Learned new things & C2 & 23 & $32 \%$ \\
\hline Praise for other team members & C1 & 23 & $32 \%$ \\
\hline Made friends & C1 & 21 & $30 \%$ \\
\hline
\end{tabular}

Table 2: Most common themes and categories which emerged in student reflections after the project $(n=71)$

The three categories and their associated themes are used as a framework for summarizing experiences the students described. Most students provided balanced reports of positive and negative aspects of the project, and most did not shy away from mentioning the difficult or negative elements of the project in their reflections, as well as introducing topics not expressly identified in the prompts. Nevertheless, we do acknowledge that this is self-reported data provided by students as part of a graded assignment, worth $5 \%$ of their overall project grade. The students' willingness to voice opinions openly provides us some assurance, however, that they aimed to provide valid reflections.

\subsection{C1: Working in a team and learning from others}

Themes in this category related to teamwork and students' interactions with their teammembers. A large percentage of the overall comments fell into this category, which highlighted some of the transferrable skills that students gained from this exercise that reflect those they will need in engineering practice. 


\subsubsection{Positive team experience}

Teamwork was referred to frequently within the reflections, with group-work presenting several challenges for students, challenges that were more easily overcome in some groups than others. Within this sample group, 73\% of students reported having a positive team experience overall. Participants described "great communication" (F5, M58), noting that "all members of the group contributed" (F8). They enjoyed the "flexibility of the team" (M53) and found that "the team would give advice, opinions and help" (M54). Many described a "sense of not wanting to let your team member down” (F9).

\subsubsection{Learning about personalities}

Under this theme, students noted how much they had learned about their teammates’ personalities through working together for the six-week period. Some said this helped them "assign people into different roles to complement their strengths" (M2), and that this resulted in a better bridge construction. Many learned about how their other team members "worked under pressure" (F4), due to the deadlines imposed. A couple of students reflected on the range of personal attributes they had encountered: "Some were extremely demanding and impatient, some were too open and narrow minded, some were too shy and introverted, some were lazy at times, some didn't realise what they were and were not good at” (M43). For one student, dealing with a team member who he initially found difficult "gave me a fantastic insight into how to handle someone, as a project manager, who... just argues for the sake of it” (M18).

\subsubsection{Negative team experience}

About half as many reflections mentioned negative team experiences as positive ones. Some of these referred to the negative impact of poor communication skills on the team 
as a whole, saying "lack of communication led to work not being completed properly" (M48) or group members were "not communicating in meetings" (M12). Other issues that arose were that the team "would not agree on ideas" (M16) and not all members were contributing “an equal amount” (F9, M5, M57, M6, M7).

\subsubsection{Praise for other team members}

Comments under this theme often mentioned a specific skill or attribute a team member had contributed to the project: " $B$ did brilliantly in working out the tension and compression forces" (F1) or " $C$ was a good addition to the team, a hard working, hands on team member who had great ideas” (F9). Almost a third of students made comments under this theme, showing that they were developing an awareness of the contributions and strengths of others on their team - an important attribute in future engineering practice, which is so frequently team-based.

\subsubsection{Made friends}

The theme of making new friends via the project emerged during analysis, although this topic was not specifically queried among these first-year students, nor indicated as a learning outcome at the start. Some students cited as an unexpected benefit, saying the project "was a surprisingly good method of introducing students to each other" (M12) and that "you get to see different sides to people" (M58). One student mentioned making friends "from different countries" (M8), while another stated that-although he had been anxious meeting new people in the past—-he formed good friendships via this project and now "I am more likely to be comfortable in a situation like that again if it were to arise” (M45). Given the difficulties that many students experience when transitioning from secondary to tertiary education, a benefit such as this emerging from a project is significant. 


\subsection{C2: Individual Development - Skills and abilities gained and self-realisation}

This category was concerned more with students' development as individuals, in terms of improved skills and realisations about their own strengths and weaknesses. There was some overlap with the skills studied in the survey, but a number of new points also emerged from the reflections.

\subsubsection{Improved confidence}

It is not surprising that "improved confidence” featured highest among themes, given that the students were directly prompted (in the instructions for reflection) to discuss the impact of the project on their confidence. Nevertheless, we found it insightful that nearly all references to confidence were positive, with $77 \%$ of reflections mentioning specific improvements in confidence resulting from this project. Many comments mentioned increased confidence in presenting work. Some described a new sense of confidence in their own opinions and ideas. The experience "boosted my selfconfidence in not only presenting our group's research but also... in my opinions and ideas” (F5). Many born outside Ireland mentioned improved confidence in their ability to communicate with a group in English.

\subsubsection{Improved presentation skills}

Regarding class presentations, students described everything from being “quite apprehensive” (M27) to having an "incredible fear" (F9) of speaking in public, with one student stating that making presentations was "the thing of nightmares for me and I have lost a lot of sleep over it in the past” (M39). Many students shared that the short presentations earlier in the project helped with making the main presentation in week four, as “having already stood up in front of everyone, I didn't feel nervous doing it again which allowed me to just focus on what I was presenting” (M27). The 
requirement for all students to be involved in repeated presentations during the project yielded success for many, with individual students noting that "practice makes perfect" (M29) and "preparation is key" (M33). Some specific presentation skills cited were to "make the presentation more fluid” (M20), "project my voice” (M41) and to "speak with confidence” (F7). This was not a skill that we had asked about during the earlier survey, but given its prevalence in the reflections, students clearly felt strongly about their improvements in this area, with clear gains for engineering practice as a result.

\subsubsection{Learned new things}

A third of all respondents mentioned learning new things - some of these things were technical, engineering- and career-related, but others were managerial and socio-cultural - some were those mentioned in the survey, but many were not. Students described having learnt "skills in drawing, presenting, teamwork, and communication" (F10), "scaling and drawing joints" (F1), and "to solve problems by doing research" (F6). The group-work structure with its intermittent deadlines helped students learn "to manage my workload within a designated time limit” (M27), "the importance of teamwork, communication, management and leadership” (M57), “listening to others” ideas" (M8) and "to think things over many times before making my mind up to make sure we do it right” (F10). Discovering and implementing new ways of allocating work, tracking progress, and holding each other accountable were central within this theme.

\subsubsection{Ambitions for future projects}

Comments here tended to be very specific, such as "messed up some of the measurements and had to do some...again so in future I will double check” (M35), or "if I were to redo this project I would have used a wider variety of books or possibly more reliable journals”(M39). Others spoke about improving skills that they realised 
needed work: "Next time, I would like to share more ideas with the group” (M21) or "I was unwilling to step outside my comfort zone... for another project, I would consider taking that jump into a different method” (M12).

\subsection{C3: Reflections on the project itself}

This final category focused on specific comments about the project itself. Only one theme under this category featured in the top ten, and this focused on the students' enjoyment of the overall experience.

\subsubsection{Enjoyed project}

In total, almost half the reflections explicitly mentioned enjoying the experience. Some comments referred to enjoying the overall project, while others described enjoyment of specific aspects, ranging from “acting as project manager" (F11) and "doing the research" (F6) to "the building process" (M1) and "working as part of a group” (M48). Providing students with the opportunity to experience the reality of fulfilling roles such as these gave them valuable insight into engineering practice as an early stage of their university career.

\section{Discussion}

In approaching this study, the main research question we aimed to answer was 'Do students perceive PBL projects to be a valuable teaching pedagogy to embed engineering practice into early engineering education, by enhancing their professional skills?' Having analysed both the survey responses and those of the students' personal reflections, it is clear that many of the issues they raised resonate with the findings of Trevelyan (2014) in his study of engineering practice. He attested that 25-30\% of professional engineering practice relates to technical co-ordination - co-ordinating the 
work of others - and to do this successfully, engineers must be able to influence other people and in doing so, build relationships. Across the three survey questions considered, students perceived that their biggest improvement during the course of this project was in relation to teamwork. Given that $78 \%$ said that they had "often" or "very often” experienced teamwork in the past (Figure 1), making it the skill with which they had the greatest familiarity prior to this project, and 75\% ranked themselves as "good" or "very good" before taking part in the project (Figure 2), it is noteworthy that this skill ranked highest in terms of their own perceived improvement. This highlights the fact that students may have been unaware of their own lack of knowledge regarding good teamwork prior to the project, or that the five-point scale simply did not allow students to adequately express the impact of the project upon their skill-set, something that should be borne in mind when researching the impact of such projects in the future. The inclusion of the survey question allowing them to rank their improvement has afforded a further glimpse into student perception of the project impact, allowing a student who previously ranked themselves as "very good” in a skill to express how they have still improved further as a result of taking part.

Working in a team and learning from others also emerged as a main category of responses from the students' personal reflections. A close analysis showed that, despite some negative experiences with teamwork (workload issues, disappointing results, conflict), every student described positive learning that resulted from working with a group. The social bonds, sense of achievement, feelings of enjoyment, and overall satisfaction with the team and its work received much more attention from students than did negative aspects of teamwork, with twice as many respondents making positive comments as negative. As students move from secondary to tertiary education, positive learning experiences such as this can help them to form bonds with their classmates, and 
the theme of making friends emerged strongly from the reflections. As such, the social aspect of working in teams and, in particular, learning about others was highlighted as a significant part of the students' experiences of this PBL project. Again, this echoes the work of Trevelyan, who attested that the greatest challenge that engineering graduates face on their path to become an expert engineer is the need to "learn about yourself and others” (Trevelyan 2104, 241).

Student comments suggested that the scaffolded approach provided helped them to improve their skillset as they transitioned into higher education. The supports most frequently noted were the written project brief with team management tools and templates; having teammates to count on; having tutors available for guidance; and being able to build and tests their designs. Important tools embedded in the project brief were those that discussed possible team structures, methods for allocating work and templates for identifying expectations/roles/penalties, developing a team charter, recording minutes and tracking performance, and for reports. Student comments affirm that this scaffolding helped them develop far-ranging non-technical skills. Being part of a team helped them modify behaviours during the design and construction process. Half of all participants described new understandings of engineering as a career as a result of taking part in the project.

In terms of communication skills, again there was a positive percentage gain in students’ self-reported improvements in this area, which agrees with the work of Fernandes (2014) that PBL is an effective teaching pedagogy for enhancing communication skills. However, it is interesting to note that "Communication" was the only skill in which fewer students ranked themselves as "very good" after the project than did before the project (see Figure 2), in spite of this perceived improvement. It may be that some of the within-group difficulties that emerged from the personal reflections 
led students to reflect again on this skill, as many of the negative team experiences reported related in some way to a lack of effective communication within the team involved.

Students' "Understanding of the Design Process” followed a more predictable path, with all three figures telling a similar story, with students declaring a $61 \%$ mean improvement in this area - unsurprising for a first-year cohort reporting on their first opportunity to design a product. This practical, hands-on introduction to some of the realities of engineering practice provided students with valuable insights into their future career, with many students expressing their ambitions for future projects of this type, both academic and professional. The results shown in Figure 3 also agree with previous studies that have shown that PBL is an effective teaching approach to improve independent research (Ahern 2010), as well as technical knowledge (Baharam et al. 2012), which corresponds to "Structural Analysis" in our study.

It was of particular interest to us, in attempting to address our research question, to determine whether there were areas in which PBL did not enhance the development of professional skills. No such areas appeared from either the survey of students or the analysis of the reflections. The two lowest perceived mean improvement scores were Technical Drawing (41\%) and Project Management (47\%). At the beginning of the project, each team member chose from roles provided such as Project Manager, Bridge Designer, Health and Safety Consultant, Technician and so on. As a result, only one team member had the opportunity to directly develop skills in these areas, which likely explains the slightly lower scores for these two skill-sets. As a result, in future iterations of this project, each student took on two roles instead of one, allowing more students to benefit from the opportunity to further improve in these specific areas. 


\section{Conclusion}

In this paper, we set out to investigate student perceptions of a PBL design project and their self-reported improvements in a variety of technical and non-technical skills as a result. We also analysed their personal reflections having undertaken the project. The project was designed to introduce students to the world of engineering practice at an early stage in their higher education, so that they would experience professional skills as embedded within their degree programme. Students were overwhelmingly positive about the project and considered that they had improved across a wide range of skills. Based on the feedback from the reflections, we advocate that teachers provide scaffolding for PBL group-work, with tools, such as written briefs, recommendations for allocating work, tracking progress, and reporting performance. Such tools help students plan their work, distribute tasks, agree upon marking/grading structures, and address interdependencies. They provide examples to help students succeed and new competencies that individuals can take forward. The scaffolding our participants described helped them succeed, and the insight we gained has helped us to enhance the supports for students in this project in subsequent years.

From the students' feedback, it would seem that PBL functioned as an effective teaching pedagogy to enhance professional skills for engineering students. However, unless the PBL project is designed with specific professional skills in mind, it could lack opportunities to develop particular graduate attributes, so the design of the project itself is also of critical importance. This was the first year that the project had been implemented in this fashion and it would be useful to investigate on a longitudinal study how effective this project was in preparing students for further years of study and the eventual skills required of them as they transition from higher education into engineering careers in the future. 


\section{REFERENCES}

Abdullah S.R.S., Takriff M.S., Ismail M., Kalil M.S., Daud W.R.W., Mohammad A.B., Rahman R.A., Mohammad A.W., Anuar N., Abdullah N., Harun S., Kamarudin S.K., Tasirin S.M., Yaakob Z., Jahim J., Kofli N.H.T., Markom M., Rahman N.A., Rahim R.R.R.A.A., and Rahaman M.S.A., (2012), Analysis of Integrated Project Effectiveness in the Implementation of Generic Skills, Procedia- Social and Behavioural Sciences, 60, pp. 512-521.

Ahern, A.A., (2010). A case study: Problem -based learning for civil engineering students in transportation courses, European Journal of Engineering Education, 35(1), 2010, pp.109-116

ASEE (2013), Transforming Undergraduate Education in Engineering Phase I: Synthesizing and Integrating Industry Perspectives, Arlington, May 9-10, 2013 Workshop Report. Retrieved January $21^{\text {st }} 2018$ from: https://www.asee.org/TUEE_PhaseI_WorkshopReport.pdf

ASEE, (2015) Transforming Undergraduate Engineering in Education. Accessed $23^{\text {rd }}$ September 2017 at http://tuee.asee.org/

Baharom S., Hamid R., Hamzah H. (2012). Development of a Problem Based Learning in Concrete Technology Laboratory Work, Procedia- Social and Behavioural Sciences, 60, pp. 8-13.

Barrows, H.S. (1988). The tutorial process. Southern Illinois University School of Medicine, Springfield, MA.

Beanland, D., and Hadgraft, R. (2013). Engineering education: Transformation and innovation. Engineering education: Transformation and innovation, xii.

Clarke, B. (2012). The 2011 James Forrest Lecture-engineering education-a historical perspective of the future. Civil Engineering and Environmental Systems, 29(3), $191-212$.

Cohen, L., Manion, L., \& Morrison, K. (2011). Research methods in education. Routledge.

Crosthwaite C., Cameron L., Lant P., and Lister J., (2006), Balancing Curriculum Processes and Content in a Project Centered Curriculum: In pursuit of Graduate Attributes, Education for Chemical Engineers,1,pp. 39-48

De Figueiredo, A. D. (2014). “On the historical nature of engineering practice.” In Engineering Practice in a Global Context: Understanding the Technical and the 
Social, edited by Bill Williams, José Figueiredo and James Trevelyan, 7-32. CRC Press.

De Graaf, E. and Kolmos, A. (2003). Characteristics of problem-based learning. International Journal of Engineering Education, 19, 657-662.

Fernandes S., (2014), Preparing graduates for professional practice: findings from a case study of Project-based Learning (PBL), Procedia- Social and Behavioural Sciences,139, pp.219-226.

Glaser, B.G., Strauss, A.L. and Strutzel, E. (1968). The discovery of grounded theory; strategies for qualitative research. Nursing research, 17(4), 364.

Grant, C.D., and Dickson, B.R., (2006), Personal Skills in Chemical Engineering Graduates: The Development of Skills Within Degree Programmes to meet the Needs of Employers, Education for Chemical Engineers, 1, pp. 23-29.

Grinter, L. E., (1955). Report on the evaluation of engineering education. Journal of Engineering Education, 46(1), 25-63. Retrieved 23 ${ }^{\text {rd }}$ April 2018 from https://www.asee.org/papers-and-publications/publications/The-Grinter-ReportPDF.pdf

Guba, E. G., \& Lincoln, Y. S. (1994). Competing paradigms in qualitative research. Handbook of qualitative research, 2(163-194), 105.

Iborra M., Ramirez E., Tejero J., Bringue R., Fite C., and Cunill F., (2014), Re-vamping of teaching-learning methodologies in laboratory subjects of the Chemical Engineering undergraduate degree of the University of Barcelona for their adjustment to the Bologna process, Education for Chemical Engineers, 9, 2014, pp.e43-e49.

IET (2016) Skills and Demand in Industry: Overview of issues and trends from 2016 survey. Retrieved 23 ${ }^{\text {rd }}$ April 2018 from http://www.theiet.org/factfiles/education/skills2016-page.cfm

IOT Report, (2011), Engineering graduates: Preparation and Progression. Institutes of Technology Honours Bachelor Degree Engineering Graduate Study. Dublin Institute of Technology, p.8.

Kirby, R. S. (1990). Engineering in history. Courier Corporation.

Kovesi, K. and Csizmadia, P. (2016) Industry perception of new engineering graduates: the gap between requirements and reality. In Proceedings of the 44rd Annual SEFI Conference. 
Le K.N., and Tam V.W.Y., (2008) On generic skill development: an engineering perspective, Digital Signal Processing, 18, 2008, pp. 355-363

Leonard-Barton, D. (1995). Wellsprings of knowledge: Building and sustaining the sources of innovation.

Marton, F., \& Säljö, R. (1976). On qualitative differences in learning: I—Outcome and process. British journal of educational psychology, 46(1), 4-11.

Miller, R., (2015). Why the hard science of engineering is no longer enough to meet the 21st century challenges. Olin College, May. Accessed 23 ${ }^{\text {rd }}$ April 2018 from http://www.olin.edu/sites/default/files/rebalancing_engineering_education_may 15.pdf

Mills, J.E. and Treagust, D.F., (2003). Engineering education — Is problem-based or project-based learning the answer. Australasian journal of engineering education, 3, 2-16.

Palmer, C. (1990). 'Hybrids'-a critical force in the application of information technology in the nineties. Journal of Information Technology, 5(4), 232.

Phillips, D., (2007), Bridge Building Using Teamwork, International Symposium for Engineering Education, Dublin, pp85-90.

Prichard, J.S., Stratford, R. J. and Bizo, L.A. (2006). Team-skills training enhances collaborative learning. Learning and Instruction, 16, 256-265.

RAE (2007) Educating Engineers for the $21^{\text {st }}$ Century. Royal Academy of Engineering. Accessed $23^{\text {rd }}$ April 2018 at https://www.raeng.org.uk/publications/reports/educating-engineers-21st-century

Sageev, P., \& Romanowski, C. J. (2001). A message from recent engineering graduates in the workplace: Results of a survey on technical communication skills. Journal of Engineering Education, 90(4), 685-693.

Savin-Baden, M., \& Major, C. H. (2013). Qualitative research: The essential guide to theory and practice. Routledge.

Seely, B.E., (1999). The imbalance of theory and practice in American Engineering Education: Reforms and Changes 1920-1980. Icon, 5, 40-63. Retrieved $25^{\text {th }}$ February 2018 from http://www.jstor.org/stable/23786075

Sheppard, S. D., Macatangay, K., Colby, A., \& Sullivan, W. M. (2009). Educating engineers: Designing for the future of the field (Vol. 2). Jossey-Bass.

Spinks, N., Silburn, N., and Birchall, D. (2006). Educating engineers for the 21st century: The industry view. London: The Royal Academy of Engineering. 
Accessed $23^{\text {rd }}$ April 2018 via

http://www.raeng.org.uk/publications/reports/educating-engineers-for-the-21stcentury

Thomas, D.R. (2006). A general inductive approach for analyzing qualitative evaluation data. American journal of evaluation, 27, 237-246.

Trevelyan, J. (2010). Mind the gaps: engineering education and practice. In Proceedings of the 21st Annual Conference for the Australasian Association for Engineering Education (p. 383). Engineers Australia.

Trevelyan, J. (2014). The making of an expert engineer. CRC Press.

UNESCO (2010), Engineering: Issues, challenges and Opportunities for Development, Paris. Accessed $23^{\text {rd }}$ April 2018 via http://unesdoc.unesco.org/images/0018/001897/189753e.pdf

Veldman F.J., De Wet M.A., Ike Mokhele N.E., and Bouwer W.A.J.,(2008) Can engineering education in South Africa afford to avoid problem-based learning as a didactic approach?, European Journal of Engineering Education, 33(5-6), pp. 551-559.

Williams, B. and Figueiredo, J. (2014) "Finding workable solutions: Portuguese engineering experience”. In Engineering Practice in a Global Context: Understanding the Technical and the Social, edited by Bill Williams, José Figueiredo and James Trevelyan, 159-184. CRC Press.

Wulf, WM.A, (2008). The Urgency of Engineering Education Reform, The Bridge Vol. 28, No. 1. Retrieved January $23^{\text {rd }} 2018$ from: https://www.nae.edu/Publications/Bridge/EngineeringCrossroads/TheUrgencyof EngineeringEducationReform.aspx 